\title{
Gabriella Morreale de Escobar (1930-2017)
}

\author{
F. Trimarchi ${ }^{1} \cdot$ P. Vitti ${ }^{2}$
}

Received: 19 March 2018 / Accepted: 20 March 2018 / Published online: 26 March 2018

(C) Italian Society of Endocrinology (SIE) 2018

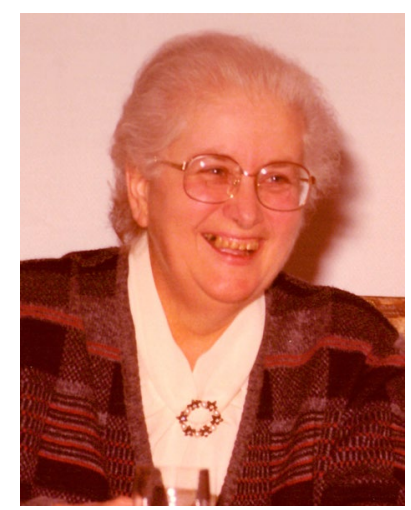

Gabriella Morreale de Escobar passed away in Madrid on December 4, 2017. She was born in Milan, Italy in 1930 and received a cosmopolitan education, having attended schools in Austria and in US, before taking the Baccalaureate in Spain. She graduated in Chemistry at the University of Granada, Spain, where she earned the Doctoral degree. Thanks to an original method for iodine measurement, she proved the strict relation between the iodine content in water and the goiter endemia in a mountainous region near Granada. Based on this relevant demonstration, Gabriella and her husband, the late Prof. Francisco Escobar del Rey, spent a post doctoral stay in Leiden, The Netherlands, under the mentorship of Andries Querido, and performed pioneristic researches on thyroid hormone metabolism, investigated by employing radioisotopes. In 1958, Gabriella Morreale de Escobar went back to Spain as a staff member of the Consejo Superior de Investigaciones Cientificas. Since 1974, she was professor at the Faculty of Medicine of the Autonomous University of Madrid where she was, with her husband, co-founder of the Instituto de Investigaciones Biomedicas.

F. Trimarchi

francesco.trimarchi@unime.it

1 Accademia Peloritana dei Pericolanti at the University of Messina, Messina, Italy

2 Unit of Endocrinology, Azienda Ospedaliero-Universitaria Pisana, University of Pisa, Pisa, Italy
The early research lines carried out by Gabriella Morreale the Escobar belong to the field of translational endocrinology in that they were based on animal studies which demonstrated the role of $\mathrm{T} 4$ as a prohormone and the concept of $\mathrm{T} 3$ tissue production regulation by $\mathrm{T} 4$ tissue levels. As stated by her fellows "... against the old thinking that the placenta was impermeable to thyroid hormones, she demonstrated that there is a transfer of thyroid hormones from mother to fetus from early gestational stages, and that maternal transfer of T4 is important for fetal brain development, raising the question that maternal hypothyroxinemia, and not maternal hypothyroidism, was detrimental to the fetus" [1]. These and other studies of clinical interest, such as the implementation of neonatal screening for congenital hypothyroidism, were the scientific basis for the introduction of iodized salt prophylaxis in Spain.

Gabriella was very active and influential in national and international scientific settings. She was one of the founders of the European Thyroid Association in 1967, and President from 1978 to 1980. She was awarded of the European Thyroid Association Prize in 1985 and the Serge Lissitzky Career Award in 2009. She was an internationally acclaimed and brilliant authority in the field of basic and translational thyroidology and an illuminated and open mentor for several generations of scientists. Thanks to her intense scientific and personal relations with Nino Salvatore and Aldo Pinchera and with the entire Italian Thyroid community, Gabriella attended frequently to scientific meetings organized in Italy, always showing her warm and wonderful personality with an open and friendly character towards everybody. In our respective capacity of former and present President of Italian Society of Endocrinology and on behalf of Italian endocrine community, we express our condolences to an outstanding scientist with a special personality who has left a very relevant cultural and personal legacy.

\section{Reference}

1. Bernal J, Obregon MJ, Santisteban PS (2018) In Memoriam: Gabriella Morreale de Escobar. Eur Thyroid J 7:109-110 